\title{
Strategi Pengembangan Destinasi Wisata dalam Meningkatkan Pendapatan Asli Daerah: Studi Taman Wisata Alam Mangolo (Kea- Kea) di Kabupaten Kolaka
}

\author{
Ilmainar Mauna ${ }^{1} ;$ Asriani $^{2} ;$ Liwaul $^{3}$ \\ ${ }^{1}$ Universitas Halu Oleo, ilmaimip@gmail.com
}

\begin{abstract}
Abstrak
Penelitian ini bertujuan untuk mengetahui Strategi Pengembangan Destinasi Wisata Taman Wisata Alam Mangolo (Kea-Kea) Guna Menambah Pendapatan Asli Daerah (PAD) Di Kabupaten Kolaka. Penelitian ini dilakukan di Dinas Pariwisata Kabupaten Kolaka. Penelitian ini menggunakan metode deskriptif kualitatif yang didukung data berupa tabeltabel dan data yang diperoleh dari wawancara, observasi langsung dan dokumentasi. Pengumpulan data ini dilakukan dengan cara purposive sampling. Sedangkan teknik analisis menggunakan model analisis interaktif dengan mendasarkan pada pengumpulan data, reduksi data, penyajian data dan penarikan kesimpulan. Hasil temuan dalam penelitian ini menunjukkan bahwa strategi pengembangan yang dapat dilakukan Dinas Pariwisata kedepannya dalam pengembangan destinasi wisata yaitu melakukan Penataan Area, Pembenahan Area dan Pembangunan Fasilitas Umum.
\end{abstract}

Kata kunci : Pengembangan, Pendapatan. Strategi, Wisata

\begin{abstract}
This study aims to determine the development strategies for Mangolo tourism (Kea-Kea) in order to improve the Original Local Government Revenue in Kolaka.This research was conducted in Tourism Department in Kolaka. The applied research method was descriptive qualitative supported by the information summarized in tables and the collected information for interviews, direct observations and documentations. The purposive sampling was used to find out the needed data. The analysis technique was analysis interactive model based on data collection, data reduction, data presentation and conclusion formulation. The results show that the used development strategies to be implemented in Mangolo tourism are the area arrangement, the area renovation and the public facilities improvement.
\end{abstract}

Keywords : Development, Revenue, Strategies, Tourism 


\section{Pendahuluan}

Pendapatan Asli Daerah (PAD) memiliki peran penting dalam rangka pembiayaan pembangunan di daerah. Berdasarkan potensi yang dimiliki masingmasing daerah, peningkatan dalam penerimaan PAD ini akan dapat meningkatkan kemampuan keuangan daerah. Seiring dengan perkembangan perekonomian daerah yang semakin terintegrasi dengan perekonomian nasional dan internasional, maka kemampuan daerah dalam mengoptimalkan pemanfaatan sumber-sumber penerimaan PAD menjadi sangat penting. Pendapatan Asli Daerah (PAD) adalah cerminan kemandirian suatu daerah dalam menyelenggarakan otonomi daerah. Namun kenyataannya masih banyak daerah yang mengandalkan bantuan dari pemerintah pusat. Hal tersebut terjadi karena banyak daerah yang tidak menyadari potensi dari sektor-sektor PAD yang ada di daerah mereka dan tidak menjadikan daerah mereka sebagai daerah potensial sumber PAD. (Hanif Nurcholis, 2007)

Pendapatan Asli Daerah (PAD) merupakan gambaran potensi keuangan daerah yang pada umumnya mengandalkan usur pajak daerah dan retribusi daerah. Berkaitan dengan hal tersebut, terdapat berbagai sektor yang dapat dikembangkan untuk meningkatkan pendapatan asli daerah, diantaranya adalah: sektor perdagangan, sektor jasa, sektor pertanian, sektor pariwisata dan lain-lain. Salah satu pendapatan pemerintah daerah adalah dari sektor pariwisata.

Pariwisata sebagai salah satu potensi daerah yang tentu akan menjadi ciri khas suatu daerah, pengembangan dan pengelolaan pariwisata di Indonesia sangatlah baik, terbukti dengan banyaknya destinasi tempat wisata yang dimiliki Indonesia, pariwisata juga menjadi salah satu penambah devisa negara yang cukup besar. Usaha mengembangkan dunia pariwisata Indonesia ini didukung dengan Undang-undang nomor 10 Tahun 2009 Tentang Kepariwisataan yang menyebutkan keberadaan obyek wisata pada suatu daerah akan sangat menguntungkan, antara lain meningkatnya Pendapatan Asli Daerah (PAD), meningkatnya taraf hidup masyarakat, dan memperluas kesempatan kerja mengingat semakin banyaknya pengangguran saat ini. 
Kabupaten Kolaka merupakan salah satu dari beberapa daerah yang menjadi daerah destinasi wisata di Provinsi Sulawesi Tenggara yang memiliki banyak obyek wisata yang perlu dikembangkan guna dijadikan sebagai peluang untuk meningkatkan Pendapatan Asli Daerah. Kabupaten Kolaka memiliki beberapa kawasan yang berpotensi untuk dikembangkan menjadi daerah obyek tujuan wisata. Terdapat 12 objek wisata potensial yang tersebar dibeberapa Kecamatan di Kabupaten Kolaka yang harus terus dikembangkan oleh pemerintah daerah. Yakni Pantai Tamborasi, Pantai Pasir Putih Tanjung Malaha, Pantai Pasir Putih Kaju Angin, Pantai Pasir Putih Poturua, Taman Wisata Alam Kea-Kea, Pantai Harapan, Pulau Padamarang, Replika Rumah adat Mekongga, Goa Watu Wula dan Air Terjun Toro Ue, Cerobong Pemantau (Peninggalan Jepang), Makam Sangiani Bandera dan Bandara Sangiani Bandera.

Adapun salah satu obyek wisata yang akan diangkat dalam proposal ini adalah Taman Wisata Alam Ulunggulaka (Kea-Kea) yang terletak di Kabupaten Kolaka Kecamatan Latambaga, yang dimana mengingat animo masyarakat yang sangat tinggi akan tempat wisata tersebut. Melihat hal tersebut, sektor pariwisata di Kabupaten Kolaka perlu mendapat perhatian dari pemerintah daerah, mengingat destinasi ini adalah destinasi baru yang dimiliki Kabupaten Kolaka. Untuk itu diperlukan sebuah strategi yang matang yang mempunyai potensi besar akan berhasil dan membawa perubahan yang lebih baik di berbagai bidang. Disinilah pentingnya peran dan kesadaran dari pemerintah daerah yang melaksanakan pembangunan di sektor pariwisata. Berdasarkan latar belakang di atas tulisan ini bertujuan tujuan untuk mengetahui Strategi Pengembangan Strategi pengembangan destinasi wisata taman wisata alam Mangolo (Kea-Kea) guna menambah Pendapatan Asli Daerah (PAD) di Kabupaten Kolaka.

\section{Metode}

Penelitian ini bersifat analisis deskriptif kualitatif. Penelitian ini dilaksanakan diwilayah Kabupaten Kolaka Provinsi Sulawesi Tenggara dengan obyek penelitian pada Taman Wisata Alam Mangolo (Kea-Kea). Lokasi ini ditentukan karena tempat ini merupakan salah satu destinasi wisata lokal baru yang 
banyak diminati. Informan yang akan diwawancarai dilakukan secara puposive sampling yaitu Kepala Dinas Pariwisata Kabupaten Kolaka, Sekretaris Dinas Pariwisata Kabupaten Kolaka, Kepala Bidang Pembukuan dan Pelaporan, serta beberapa masyarakat yang merupakan pengunjung obyek wisata Taman Wisata Alam Mangolo (Kea-Kea).

Sumber data yang digunakan dalam penelitian ini adalah mencakup data primer dan data sekunder .Data primer yaitu data yang diperoleh dari sumber pertama dan diperoleh melalui studi lapangan. Data diperoleh dari sumber pertama atau informan secara langsung sebgai objek penelitian dengan cara melakukan wawancara langsung dilokasi penelitian. Teknik analisis data yang dilakukan dalam penelitian ini adalah analisis deskriptif kualitatif. Menurut Miles dan Huberman dalam (Sugiyono, 2015) aktivitas dalam analisis data kualitatif dilakukan secara terus menerus sampai tuntas, sehingga datanya sudah jenuh. Aktivitas dalam analisis data yaitu pengumpulan data (Collection), reduksi data (Reduction), penyajian data (Display), dan penarikan kesimpulan/ verifikasi (conclusion/Vervicatio).

\section{Hasil dan Pembahasan}

\section{Strategi Pengembangan}

Strategi pengembangan pariwisata adalah upaya-upaya yang dilakukan dengan tujuan memajukan, memperbaiki, dan meningkatkan kondisi kepariwisataan suatu obyek dan daya tarik wisata sehingga mampu menjadi mapan dan ramai untuk dikunjungi oleh wisatawan. Mampu memberikan suatu manfaat baik bagi masyarakat di sekitar obyek dan daya tarik dan lebih lanjut akan menjadi pemasukan bagi pemerintah dan menjadi cerminan keberhasilan sebuah system pariwisata yang baik. Adapun strategi pengembangan yang dimaksud yakni :

\section{a. Penataan Area}

Penataan area merupakan suatu kawasan yang disediakan untuk kegiatan wisata. Penataan area bertujuan untuk memudahkan wisatawan menemukan lokasi atau fasilitas yang diinginkan. Pembangunan pintu gerbang merupakan satu hal yang penting, karena pintu gerbang akan menjadi acuan dan patokan wisatawan 
untuk masuk ke area wisata. Berdasarkan hasil penelitian, penataan area di Taman Wisata Alam Mangolo (kea-kea) seperti pembangunan pintu gerbang belum tersedia. Hal ini seperti yang diungkapkan oleh Sekretaris Dinas Pariwisata Kab. Kolaka mengungkapkan bahwa "Memang untuk Taman wisata alam Mangolo ini penataannya belum memadai, Namun kami selaku pemerintah yang bertanggung jawab dalam hal ini, sedikit demi sedikit sudah melakukan. Contohnya di jalan masuk menuju lokasi utama taman wisata kea-kea ini, kami membangun spot foto yang bertuliskan I LOVE KEA-KEA sebagai tanda pengganti sementara yang secara tidak langsung menjelaskan bahwa mereka telah sampai ke destinasi wisata tersebut". (Andi Pangoriseng,2019).

Hasil wawancara sejalan dengan pendapat yang dikemukakan oleh Kepala Dinas Pariwisata yang mengungkapkan bahwa "untuk sementara memang belum ada pintu gerbang yang benar-benar dapat menjadi petunjuk arah, namun saya selaku kadis dan dengan inisiatif meminta bantuan kepada 15 Dunia Usaha, dalam hal ini untuk bisa mendapatkan dana yang lebih untuk pembangunan segala hal yang masih kurang di tempat wisata tersebut " (Akhmad Yani, 2019). Hasil wawancara tersebut didukung oleh hasil wawancara oleh salah satu wisatawan menuturkan bahwa "menurut saya pintu gerbang di lokasi wisata ini sangat diperlukan untuk kami para wisatawan, agar supaya kami mengetahui bahwa kami sudah tiba dilokasi wisata yang kami tuju". (Aldi, 2019).

Berdasarkan pernyataan diatas wisata kea-kea perlu penataan area dengan mengadakan petunjuk-petunjuk jalan dan pintu gerbang masuk wisata alam kea-kea yang ada di TWA Mangolo. Penataan area tersebut perlu dilakukan agar banyak wisatawan yang datang untuk menikmati wisata tersebut. Seperti yang di ungkapkan oleh Kepala Bidang Pembukuan dan Pelaporan "dalam penataan area wisata kea-kea perlunya kerja sama antara dinas pariwisata dan masyarakat untuk penataan yang tepat dan perlunya pintu gerbang masuk wisata agar para pengunjung wisata alam tersebut banyak yang tahu dan banyak minat untuk melakukakn liburan di wisata alam, dari penataan area tersebut berguna untuk wisatawan yang belum mengatuhi jalan menuju wisata jika masyarakat sudah banyak yang mengetahui wisata tersebut pasti pendapatan dapat meningkat tiap tahunnya. (Awiyah, 2019) 
Berdasarkan hasil wawancara dan observasi di atas, dapat disimpulkan bahwa penataan area belum sepenuhnya terlaksana, karena pembangunan pintu gerbang yang dimana menjadi salah satu hal intim yang perlu ada disuatu lokasi wisata justru belum ada tetapi dalam hal ini Dinas Parwisata perlu bekerja sama masyarakat agar penataan perlu cepat dilakukakan agar pendapatan daerah tersebut dapat meningkat.

\section{b. Pembenahan area}

Pembenahan area dibutuhkan dalam pengembangan, yang dimana jika pembenahan dilakukan dengan baik akan menjadi penarik minat wisatawan untuk berkunjung ke destinasi tersebut. Pembenahan yang dilakukan dengan baik akan berdampak baik bagi tempat wisata tersebut. Pembenahan area yang dimaksud adalah memaanfaatkan setiap lahan kosong yang mungkin masih bisa untuk membangun fasilitas yang kurang. Contohnya penambahan warung, gazebo, cottage dan toilet. Penambahan fasilitas lain juga seperti Spot foto, taman bermain anak dan tempat sampah sehingga memudahkan serta memanjakan wisatawan dalam melakukan kegiatan wisatanya. Hal ini seperti yang diungkapkan oleh Sekretaris Dinas Pariwisata Kab. Kolaka bahwa dalam hal pembenahan area, selaku Dinas yang bertanggung jawab dalam hal ini sudah melakukan pembenahan tersebut, dapat dilihat bahwa telah ditambahnya beberapa gazebo di setiap lahan yang masih kosong. (Andi Pangorisaeng, 2019).

Hasil wawancara sejalan dengan pendapat yang dikemukakan oleh Kepala Dinas Pariwisata yang mengungkapkan bahwa "pembenahan area yang kami padukan dengan pengembangan fasilitas sudah baik. selaku pemerintah yang bertanggungjawab dalam hal ini, sedikit demi sedikit sudah pembenahan telah dilakukan. contohnya kami sudah menambah beberapa gazebo, spot foto dan taman bermain sebagai bentuk pemanfaatan area kosong sebagaimana hal ini menjadi hal penting dalam pembenahan area wisata."(Akhmad Yani, 2019). Hasil wawancara tersebut didukung dengan hasil wawancara oleh salah satu wisatawan yang yang mengungkapkan bahwa "menurut saya pembenahan area wisata kea-kea ini sudah baik. Karena pemerintah sudah memanfaatkan lahan kosong dengan membangun 
beberapa fasilitas. namun menurut saya masih ada yang kurang, yaitu perlunya lagi dibangun tambahan toilet dan ruang ganti. tapi ada plus minus dari pembenahan seperti adanya tempat sampah disetiap sudut,taman bermain dan spot foto. Penyediaan tempat sampah tersebut membuat wisatawan tidak lagi membuang sampah sembarangan serta wisatawan yang membawa anak juga sudah sangat senang dengan adanya taman bermain anak”. (Fikram, 2019). Berdasarkan hasil wawancara dan observasi diatas dapat disimpulkan bahwa pembenahan area di taman wisata alam kea-kea sudah terlaksana dengan baik.

\section{c. Pembangunan Fasilitas Umum}

Fasilitas umum wisata adalah salah satu hal yang dapat memenuhi kebutuhan wisatawan yang melakukan perjalanan wisata sesampainya di obyek wisata yang dituju.Pembangunan fasilitas yang dimaksud seperti toilet dan mushollah dimana toilet dan musholah sangat dibutuhkan. Seperti yang diungkapkan oleh Kepala Dinas Pariwisata bahwa pembangunan fasilitas umum sudah memadai. Dapat dilihat dengan keberadaan mushollah dan toilet dan tempat untuk istirahat dan makan, karena selaku pemerintah juga mengutamakan pembanguan sarana dan prasarana tersebut. Pembangunan fasilitas umum yang lainpun juga sudah dilakukan, dimana semua hal itu untuk membuat indah dan nyaman tempat tersebut sehingga dapat menarik wisatawan lebih banyak lagi. Dinas Pariwisata Kabupaten Kolaka terus melakukan pengembangan dengan menggunakan dana APBD. Selain penggunaan anggaran dari pemda, pengembangan wisata juga dibangun melalui dana bantuan dari beberapa dunia usaha yang memberikan bantuannya untuk menunjang penyediaan beberapa fasilitas" (Akhmad Yani, 2019).

Dalam strategi pembangunan fasilitas atau sarana dan prasarana untuk meningkatkan pendapatan asli daerah masyarkat dan pemerintah bekerja sama membangun fasilitas-fasilitas umum seperti toilet dan mushollah, karena kedua fasilitas ini sangat utama bagi tempat wisata. (Andi Pangoriseng, 2019). Dari tersebut diatas dapat diketahui pemerintah dan masyarakat sudah membangun sarana dan prasarana semua fasilitas yang dapat memungkinkan proses 
perekonomian berjalan dengan lancar sedemikian seperti yang diungkapkan oleh kepala Bidang Pembukuan dan pelaporan yang menjelaskan bahwa "dalam pengembangan wisata alam kea-kea perlunya sarana-dan prasarana yang dapat mengembangkan prekonomian masyarakat disana seperti tempat rumah makan, atau tempat jualan makanan kuliner agar masyarakat dapat memanfaatkan wisata alam tersebut untuk tempat berjualan"(Awiyah, 2019). Berdasar wawancara di atas juga didukung dengan hasil wawancara wisatawan mengungkapkan bahwa "menurut saya pemerintah sudah dengan baik dalam melakukan pembangunan fasilitas umum ditempat ini, namun lebih baik jika ditambah beberapa toilet lagi, karena apabila pengunjung membludak maka akan membuat antrian panjang yang meresahkan".(Ahmad, 2019).

Berdasarkan hasil wawancara dan observasi bahwa disimpulkan bahwa pembangunan fasilitas umum sudah terlaksana dengan baik di Taman Wisata Alam Mangolo (kea-kea) ini seperti pembangunan fasilitas kebutuhan wisatawan seperti fasilitas spot foto, toilet, tempat sampah, dan gazebo. Dapat disimpulkan sesuai dengan wawancara diatas bahwa adanya sadar wisata ini dapat membantu dalam pengembangan pariwisata yang dapat memberikan sumbangsih kepada daerah sesuai dengan hasil yang didapatkan. Dalam usaha ini telah dilakukan dengan adanya kerjasama dengan masyarakat yang dapat menyediakan fasilitas seperti, Warung Makan, Gazebo, toilet dan Spot Foto. Strategi pengembangan pariwisata ini harus didukung adanya sarana dan prasarana yang baik dalam menambah Pendapatan Asli Daerah (PAD).

\section{Pendapatan Asli Daerah}

Pendapatan Asli Daerah (PAD) merupakan pendapatan yang harus ditentukan dan dikumpulkan secara lokal. Sektor pariwisata ini merupakan bagian dari Pendapatan Asli Daerah (PAD) Kabupaten Kolaka yang telah memberikan sumbangsih dalam perubahan pembangunan yang lebih baik. Dari sinilah sektor pariwisata dibutuhkan pengembangan untuk dapat meningkatkan terhadap Pendapatan Asli Daerah (PAD). Dapat diketahui sektor pariwisata dapat memberikan sumbangsih terhadap Pendapatan Asli Daerah (PAD) yang sebagai 
Satuan Kerja Perangkat Daerah (SKPD). Hal ini seperti yang diungkapkan oleh Kabid Pembukuan dan Pelaporan bahwa "Taman wisata alam kea-kea ini merupakan destinasi baru yang di buka pada januari 2017 kemarin. Destinasi ini sudah masuk dalam anggaran PAD, namun belum menghasilkan karena masih sangat baru. Namun, menurut pengamatan saya sendiri ketika berada di lokasi wisata tersebut sangat besar kemungkian destinasi ini menjadi penyumbang PAD yang menjanjikan kedepannya, karena animo masyarakat untuk datang ke tempat ini sangat besar. Jadi, kemungkiann tahun depan sudah bisa di akumulasi dana yang masuk dari destinasi ini dalam pemasukan PAD itu sendiri. (Awiyah, 2019). Dapat disimpulkan sesuai dengan wawancara di atas bahwa destinasi wisata Kea-Kea ini merupakan salah satu dari beberapa destinasi yang ada yang dimana dapat menjadi penyumbang PAD untuk Kabupaten Kolaka

\section{Gambar 1.Taman Wisata Alam Ulunggolaka (Kea-Kea)}

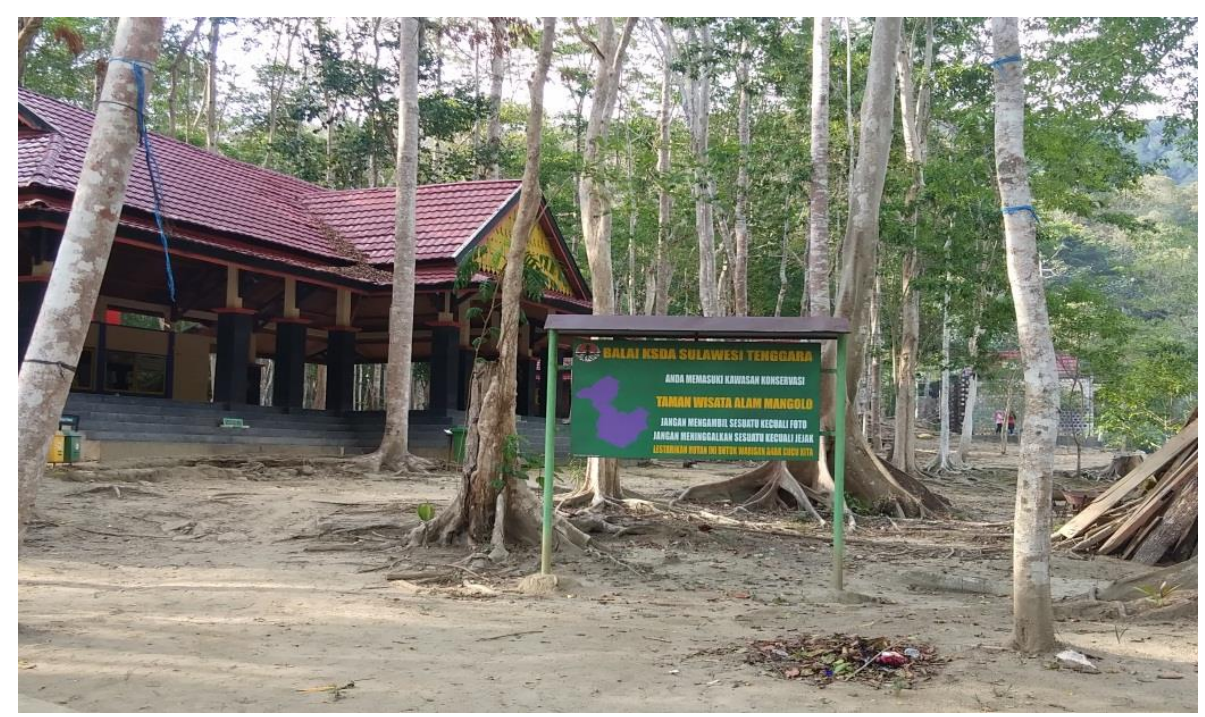

Sumber: Observasi Lapangan Taman Wisata Alam Kea-Kea, 2019

Pada tahun 2017 Pendapatan Asli Daerah untuk wisata alam Kea-Kea belum masuk Pendapatan Asli Daerah karena Wisata tersebut baru ada di Tahun 2018. Berikut dapat dilihat jumlah PAD pada tahun 2018 - 2019 pada tabel 1. 
Tabel 1. Pendapatan Taman Wisata Alam Kea-Kea

\begin{tabular}{|c|c|}
\hline Tahun & Hasil Retribusi Parkir TWA Mangolo (Kea-Kea) \\
\hline 2017 & - \\
\hline 2018 & Rp.4.000.000,- \\
\hline 2019 & Rp.9.800.000,- \\
\hline
\end{tabular}

Sumber Data: Dinas Pariwisata Kolaka, 2019

Berdasarkan data di atas dapat dilihat di tahun 2017 jumlah Pendapatan Taman Wisata Alam Kea-Kea adalah Rp.0,- ,sedangkan untuk di tahun 2018 Pendapatan Taman Wisata Alam Kea-Kea berjumlah Rp. 4.000.000, ditahun 2019 jumlah pendapatan taman wisata alam Kea-Kea meningkat dibanding tahun sebelumnya menjadi Rp.9.800.000. Adanya data tersebut bahwa pariwisata di daerah Kabupaten Kolaka dapat dikembangkan lagi karena dilihat dari potensi yang dimiliki oleh daerah itu sangat besar dan luas telah memiliki wisata budaya dan wisata alam yang mempunyai daya tarik masing-smasing dengan keindahan alam yang dimiliki sehingga pendapatan Asli Daerah (PAD) diperkirakan dapat meningkat tiap tahunnya.

\section{Kesimpulan}

Berdasarkan hasil penelitian baik melalui wawancara dan dokumentasi mengenai strategi pengembangan destinasi wisata taman wisata alam mangolo (kea-kea) guna menambah ppendapatan asli daerah (PAD) Kabupaten Kolaka dapat disimpulkan bahwa Strategi yang dilakukan dalam pengembangan destinasi taman wisata alam mangolo (kea-kea) guna menambah pendapatan asli daerah di kabupaten kolaka yaitu dengan melakukan Penataan area, pembenahan area dan pembanguann fasilitas. Yang dimana dalam pembenahan areanya masih ada sedikit kekuarangan yakni belum adanya pintu gerbang sedangkan untuk pembenahan area dan pembangunan fasilitasnya sudah memadai atau dapat dikatakan sudah baik.

Pendapatan Asli Daerah yang dihasilkan dari retribusi parkir taman wisata alam mangolo (kea-kea) sejak 2 tahun beroperasi sudah menyumbang untuk peningkatan Pendapatan Asli Daerah kabupaten Kolaka. Dalam strategi pengembangan destinasi wisata taman wisata alam mangolo (kea-kea) guna 
menambah pendapatan asli daerah di Kabupaten Kolaka, Dinas pariwisata perlu membuat pojok informasi dan menyediakan majalah yang dimana didalamnya terdapat informasi mengenai destinasi wisata tersebut serta membuat juga pondok souvenir/oleh-oleh, sehingga wisatawan yang berkunjung dapat membeli dan membawa pulang cendramata khas daerah dari tempat wisata tersebut.

\section{Referensi}

Damanik, Janianton dan Helmut F. Weber. 2006. Perencanaan Ekowisata: dari Teori ke Aplikasi. Yogyakarta: Andi

Fandeli, Chafid. 1995. Dasar-Dasar Manajemen Kepariwisataan Alam. Yogyakarta: Penerbit Liberty.

Hanif, Nurcholis. 2007. Teori dan Praktik Pemerintahan dan Otonomi Daerah. Jakarta : PT Grasindo

Ismayanti.2009. Pengantar Pariwisata. Jakarta: Grasindo

Joyosuharto S. 2000. Aspek Ketersediaan dan Tututan Kebutuhan Dalam Pariwisata Dalam "Dasar-Dasar Manajemen Kepariwisataan Alam, Yoyakarta, Editor: Ch. Fandeli, Liberty

Karyono, Hari. 1997. Kepariwisataan. Jakarta: PT Grasindo.

Kodyat, RA. 2001. Statistik Induktif Terapan. Yogyakarta: BPFE UGM

Masitoh \& Laksmi Dewi, 2009 Strategi Pembelajaran, Jakarta: DEPAG RI

Ngafenan, Mohammad, 1991. Kamus Pariwisata, Jakarta: Dahara Prize.

Pendit, Nyoman S, 1999. Ilmu Pariwisata Sebuah Pengantar. Jakarta. Perdana.PT. Pradnya Paramita.

Pitana, I. Gede. 2009. Pengantar Ilmu Pariwisata. Yogyakarta: Andi Offset.

Poerwadarminta, W.J.S. 2002. Kamus Umum Bahasa Indonesia. Jakarta : Balai Pustaka.

Prihadi, Syaiful F. 2004. Assessment Center : Identifikasi, Pengukurandan Pengembangan Kompetensi, Jakarta, PT.Gramedia Pustaka Utama. 
Rangkuti, Freddy. 1997. Teknik Membedah Kasus Bisnis-Reorientasi Konsep Perencanaan Strategis Untuk Menghadapi Abad ke-21. Jakarta: PT. Gramedia Pustaka Utama.

Ridwan, Mohammad.2012. Perencanaan dan Pengembangan Pariwisata, Bandung, PT. Softmedia.

Riwu Kaho, Josef.1997. Prospek Otonomi Daerah Di Negara Republik Indonesia (Identifikasi Beberapa Faktor Yang Mempengaruhi). Jakarta: Grafindo Persada.

Sugiyono. 2015. Metode Penelitian Tindakan Komprehensif. Yogyakarta: Alfabeta. Sunaryo, Bambang, 2013 Kebijakan Pembangunan Destinasi Pariwisata : Konsep danaplikasinya di Indonesia, Yogyakarta: Gava Media.

Suwantoro, Gamal. 1997. Dasar-Dasar Pariwisata. Yogyakarta: Andi Publishing. Suwarjoko, Warpani P. 2007. Pariwisata Dalam Tata Ruang Wilayah. Bogor. ITB. Swarbrooke, Jhon and Horner Susan. 2003. Costumer Behaviour in tourism.oxford, Butterworth-Heinemann.

Syamsu. 2001. Penerapan Etika Perencanaan pada kawasan wisata. Jakarta. LP3M STP Trisakti.

Umar, Husein : 2001, Strategic Manajement in action, Jakarta. PT. Gramedia Pustaka Utama.

Wahab, Salah. 2003. Manajemen Kepariwisataan. Jakarta, Pradnya Paramita. Wiyono, Slamet. 2006. Managemen Potensi Diri. Jakarta: PT Grasindo Yoeti, Oka, A. 2006. Pengantar Ilmu Pariwisata. Bandung, Angkasa.

\section{Wawancara}

Ahmad. (2019). Kolaka. 23 Mei 2019

Aldi. (2019). Kolaka, 23 Mei 2019

Awiah. (2019). Dinas Pariwisata Kabupaten Kolaka, 23 Mei 2019

H. Andi Pangoriseng. (2019). Dinas Pariwisata Kabupaten Kolaka, 23 Mei 2019

Yani, Akhmad. (2019). Dinas Pariwisata Kabupaten Kolaka, 23 Mei 2019

Fikram. (2019). Kolaka, 23 Mei 2019 